\title{
The application of football game in the football teaching
}

\author{
Ganjun Liu $^{1} \quad$ Jian Huang ${ }^{2}$ \\ ${ }^{1}$ Gannan Medical University, Ganzhou, Jiangxi Province, China,341000 \\ ${ }^{2}$ Gannan Medical University, Ganzhou, Jiangxi Province, China,341000
}

57385969@qq.com

\begin{abstract}
For a long time, the school's football teaching has had it with basic knowledge, basic technology, basic skills and monotonous technical teaching method, so, it is easy to make students feel bored and lose interest and confidence in football learning. In football teaching, taking the football game as an assisted instruction of football teaching not only conforms to the modern teaching thought - - teaching through lively activities, but also helps to stimulate students' learning motivation, which can improve the level of technical consciousness more comprehensively and train the students' spirit of collectivism to work solidly and cooperate closely. In addition, taking the football game as an assisted instruction of football teaching also has positive significance to improve the teaching quality.
\end{abstract}

Keywords: football teaching; football game; application and effect

\section{Introduction}

In the organization of football teaching, it is the important responsibility of every football teachers to know how to stimulate students' interest in participation and enable them to learn the knowledge and skills. Students need interest and then can have fun in practice, so when they are learning, teacher's long lecture on regular collection will make them feel a little tired and bored. Most students are interested in the positive teaching method and enjoy such teaching atmosphere.

Football game is a teaching method with a series of games in football carried out in the class teaching. Football game is mainly to build a learning atmosphere and create a suitable environment, so as to stimulate students' interest in learning and receive a good learning effect. Football game is entertaining and interesting, which is one of the most effective teaching methods in football teaching process. In the classroom teaching, football game can be introduced and applied in the objective and teaching task. Through football game teaching, students can be guided to master the sport techniques and skills, in addition, their enthusiasm and initiative of learning can be aroused as well. As football education workers, teachers must pay attention to the role of the football game in classroom teaching and use it reasonably.

\section{The role of football game in football teaching}

\subsection{Improving students' learning initiative and interest}

Football sport itself has the characteristics of intense antagonism, whose requirement for skills and tactics is particularly high. Therefore, reasonable arrangement of game as an assisted teaching method is necessary. Especially for those beginners, it can avoid the negative emotions because of monotonous, boring and difficult exercises.

If football game is applied as an assisted method in the teaching process, a lively football class can be organized. As a matter of course, it is very significant to see beginners to become familiar with football and develop their physical coordination. Meanwhile, with football game applied in football teaching, the attention of students in class can be improved and the interest of students can be stimulated in football class, as a result, they can keep psychological desire and requirement to next class.

\subsection{Improving effect of the football teaching}

It is very boring for individual to learn the basic skills of football, but teaching practice in the form of games 
can not only train students' basic technical ability, but also make students fully warm up and be engaged themselves into the classroom learning as soon as possible. At the same time, the teaching contents are also enriched, which helps to stimulate students' learning consciousness and enthusiasm, strengthen students' physical quality, raise students' level of skills and tactics, and improve the classroom teaching effect.

Football games vary from the classroom teaching content. Teachers can arrange some specialized practice of football games, which can stimulate students' interest and improve the efficiency of practice, so as to achieve the double effect with half effort. Football game can effectively arouse students' learning emotion, make them relax physically and psychologically, and then eliminate the feeling of fatigue. Through the form of games teaching, students can master all kinds of sports skills, therefore, football game teaching plays an effective role in achieving the teaching target.

\subsection{Developing the mental health}

If students often take part in football sports, their courageous tenacity and perseverance can be cultivated, what's more, fine qualities such as sense of competition, cooperation and interaction can be improved as well. Football game also has a positive effect in maintaining students' mental health by making students away from worries and anxiety in study life, thus, their positive outlook on life and world view can be built. The organization form of the football game is collective, which has a clear limit for rules with obvious antagonism, competition and technique. In the process of football teaching, football game is beneficial to cultivate the students' sentiment, team spirit, indomitable style and consciousness competition and cooperation. And, more importantly, the students can enjoy the fun of football in football game, which not only exercises physically but also psychologically.

\subsection{Promoting interaction and cooperation}

Adopting the teaching method of football game in practice requires the participation, observation and cooperation of students, and in the process of technological learning, students are willing to provide technical feedback for their companions, so that the technical problems can be found and corrected as early as possible, which also can further develop their mutual harmonious relationship. This method can obviously enhance the students' interaction in learning and coordinate relationships among students, which is more conducive to form a unity of collective style and increase the collective cohesion.

\subsection{Changing the traditional teaching concept and reflecting joyful teaching}

The traditional football teaching mode is boring in its content and stereotyped in its method, which will inevitably reduce the students' interest and motivation in learning. On the contrary, the colorful teaching contents and vivid teaching method will attract the attention of students, enable the students to obtain more new knowledge constantly and get mental satisfaction, so as to stimulate their learning enthusiasm. The application of football game precisely reflects its role in learning assistance. Combining with the characteristics of the teaching material, it changes the mode and concept of traditional teaching, creates a loose and comfortable teaching environment, overcomes the anxiety of student in the class because of the difficult movement or risky teaching process, and indirectly uses the concept of "heuristic teaching".

\section{Analysis of application of game in football teaching}

\subsection{The role of football game in warming up}

In the process of sports teaching, the purpose of the warming up is to make the respiratory system and blood circulatory system adapt to the movement state of the body in order to raise the temperature of muscle and reduce the occurrence of injury. Football class in the past used to carry out warming up activities through jogging, physical exercises and positional operand, which makes students feel bored and tired in the dull classroom atmosphere.

The football game, however, improves students' flexibility, agility, range and velocity of movement and strength of muscle through warming up activities. The arrangement of the game can be subject to the 
conditions of the season, for example, in spring and summer, teachers can arrange game exercises to train students' flexibility, agility and speed with $5 \sim 10$ minutes or so; while in autumn and winter, teachers can arrange game exercises to train students' endurance and strength with $10 \sim 15$ minutes advisable. Warming up activities, such as "snake" running, "spiral" running, "net fishing" running, "monkey ball" running, and "passing ball" running, can obtain the effect of warming up. These football games play an effective role in increasing excitability and concentration of students, and are also conducive to teaching organization. Various forms of games not only enrich the teaching content but also become means of organization.

\subsection{Application of football game in basic part}

In the basic part of the class, the task is to learn the new content and review the old content. Through special game, students can master the basic skills of football, develop their physical quality and form the fine qualities of bravery, tenaciousness and collectivism. Selective application of some games with close link to the teaching content plays a good supporting role in improving students' basic skills. After the students have mastered the basic skills of football, they can further practice in the competitive football game and understand the behavioral essentials of football. At the same time, football game can enhance their collective sense of honor, bravery and perseverance, so as to consciously enhance learning effect.

\subsection{Application of football game in technique and strategy teaching}

Technical training game is designed to overcome the monotonous and boring phenomenon in a relatively less-pressured teaching environment, which mainly concludes the following content: ball controlling, dribbling, passing, catching, head intercepting, feinting and shooting skills, etc.

Technical training is designed to make students transform the football skills learned in practice to the actual combat game. Practice time can be appropriately adjusted according to the number, content and season. The football field can be square, rectangle or round ground. Field with large space can be divided into several small regions, in addition, a number of marker tubes, marker post and portable goalposts can be set up in the field area. The biggest benefit and effect of tactical game is to learn how and when to pass the ball in the practice, how and when to hold a place facing the opponent and whether to shoot or pass in some special cases, etc. These are all the problems students face in the process of the game.

\subsection{Application of football game at the end of class}

At the end of the football class, in order to make students quickly eliminate fatigue, it is necessary to recover body from a highly excited state gradually to a relatively quiet state, which is beneficial to the physical and psychological recovery. At the end of the football class, relaxing activities can be arranged so that the students adjust their excitement in cerebral cortex after physical game.

\section{Matters needing attention in the teaching process of football game}

\subsection{Pertinence of football game teaching}

The content and application of football game should be combined with teaching task and objective. Most of the games have a common purpose, that is, whether the assisted training activities are related to the teaching task. If the main task is to develop ball catching and passing skills, football game should comply with this requirement.

\subsection{Effectiveness of football game teaching}

Game is just an assisted teaching method, which cannot be treated as important as the traditional teaching, otherwise it will not only affect the main content of football teaching, but also can cause students to form rebellious attitude and decrease students' study enthusiasm. Football games can arouse the enthusiasm and initiative of students learning and guide students to master the sport techniques and skills, playing a good role in promoting the football teaching.

So, as a football education worker, football teacher should collect information of all kinds of sports games through various channels, and then discover the reference methods for football game teaching, so as to 
lay the foundation for the further promotion of football games. According to the football teaching purpose and task, football teacher should also consider and design new football form adapted to the teaching task. Practice in class should also be organized, improved and perfected in accordance with the football game targeted to class.

\section{Conclusion}

Game teaching can effectively promote the football teaching effect and has important influence in the formation of students' physical quality and personal character. Teachers should pay attention to the relevance between football game and teaching when applying the football game in class practice, in case that football game is not effective to the class teaching. On the whole, the application of game teaching method in the football teaching can play its role effectively and promote the efficiency of football teaching.

\section{Reference}

[1]Wang Chongxi. Ball Games - Football [M].Beijing: Higher Education Press.2005:198-203

[2]Wang Xiaoxiao, Houfeng. Present situation and countermeasure analysis of college football teaching under new circumstances [J]. Sports world (academic version),2010:3: 105-106 